\title{
Ação antrópica na produção de alimentos em áreas de Brejos de Altitude no semiárido do Nordeste, Brasil
}

Os brejos de altitude são unidades biogeográficas peculiares pois são um conjunto de áreas de florestas úmidas rodeadas por vegetação xerófila típica de Caatinga. O objetivo deste trabalho foi observar a influência das alterações ambientais na produção das culturas tradicionais no município de Garanhuns, utilizando para isso dados pluviométricos extraídos da APAC e do banco de dados do IBGE, além de imagens de satélite. No total, foram coletadas séries históricas dos dados de chuva, produção agropecuária e uso do solo para o município de Garanhuns e tradadas com o uso do programa QGIS e excel para a criação de figuras e gráficos de relação. Observou-se que as áreas de florestas naturais foram reduzidas de $5 \%$ para menos de $1 \%$ durante um período de 15 anos, e que as produções tradicionais como criação de gado, plantio de mandioca, milho e feijão estão em declínio. Tal dado está vinculado às mudanças climáticas e aos processos de degradação dos solos e vegetação da região. Observou-se ainda que novas culturas estão em ascensão, como as de produção de galináceos confinados em granjas, produção de Suínos e caprinos, além de culturas como a produção de mel de abelha e a piscicultura. Desta forma, as mudanças causadas pelo homem no ambiente são relevantes no processo de desequilíbrio ambiental e perda de biodiversidade de uma região.

\section{Anthropic action in food production in Brejos de Altitude areas in the semiarid region of the Northeast, Brazil}

\begin{abstract}
The high-altitude wetlands are peculiar biogeographic units because they are a set of wet forest areas surrounded by typical Caatinga xerophytic vegetation. The objective of this work was to observe the influence of environmental changes on the production of traditional crops in the municipality of Garanhuns, using pluviometric data extracted from APAC and the IBGE database, as well as satellite images. In total, historical series of rain, agricultural production and land use data were collected for the municipality of Garanhuns and translated using the QGIS and excel program for the creation of relationship figures and graphs. It was observed that natural forest areas were reduced from $5 \%$ to less than $1 \%$ over a period of 15 years, and that traditional productions such as cattle raising, cassava planting, corn and beans are in decline. This is linked to climate change and the processes of soil and vegetation degradation in the region. It has also been observed that new crops are on the rise, such as the production of poultry confined to farms, the production of pigs and goats, as well as crops such as bee honey and fish farming. Thus, man-made changes in the environment are relevant in the process of environmental imbalance and loss of biodiversity of a region.
\end{abstract}

Keywords: Environmental economics; Production; Environmental degradation.

Topic: Uso de Recursos Naturais

Reviewed anonymously in the process of blind peer
Received: 09/08/2020

Approved: 25/09/2020
José Cleiton Souza Tenório

Universidade Federal do Agreste de Pernambuco, Brasil http://lattes.cnpq.br/4605803522318090

tenoriocleiton@gmail.com

Ana Karine Nascimento Pimentel (iD

Universidade Federal do Agreste de Pernambuco, Brasil http://lattes.cnpq.br/1034618089691633

http://orcid.org/0000-0002-8869-8698

karinepimentel.al@gmail.com

Fernando da Silva Alexandre (iD)

Universidade Federal de Pernambuco, Brasil

http://lattes.cnpq.br/4706537702201893

http://orcid.org/0000-0003-0896-9433

fnando257@gmail.com

\author{
Horasa Maria Lima da Silva Andrade \\ Universidade Federal do Agreste de Pernambuco, Brasil \\ http://lattes.cnpq.br/4314101991387960 \\ http://orcid.org/0000-0002-5366-6610 \\ horasaa@gmail.com \\ Luciano Pires de Andrade (iD \\ Universidade Federal do Agreste de Pernambuco, Brasil \\ http://lattes.cnpq.br/5367851306746294 \\ http://orcid.org/0000-0001-5818-711X \\ lucianopandrade@gmail.com
}

Referencing this:

TENÓRIO, J. C. S.; PIMENTEL, A. K. N.; ALEXANDRE, F. S.; ANDRADE, H. M. L. S.; ANDRADE, L. P.. Ação antrópica na produção de alimentos em áreas de Brejos de Altitude no semiárido do Nordeste, Brasil. Revista Ibero Americana de Ciências Ambientais, v.11, n.5, p.578-593, 2020. DOI: http://doi.org/10.6008/CBPC2179-6858.2020.005.0052 


\section{INTRODUÇÃO}

Os brejos de altitude são unidades biogeográficas inseridas no domínio Caatinga sendo caracterizados como verdadeiros conjuntos de áreas de florestas úmidas rodeadas por vegetação xerófila típica de Caatinga. São ecorregiões encontradas em grandes altitudes, geralmente, $600 \mathrm{~m}$ acima do nível do mar (FREITAS et al., 2019). Os brejos de altitude são áreas privilegiadas por uma maior influência sobre os níveis de precipitação anual, sendo então considerados áreas de refúgio para as espécies viventes no bioma Mata Atlântica (LIMA, 1982, BARBOSA et al., 2004). Tal característica é explicada, pois as serras e planaltos onde os brejos estão localizados favorecem a ocorrência de zonas de clima úmido, o que aumenta a condensação da água no ar, resultando em chuvas que garantem uma maior umidade atmosférica local. Para Silva et al. (2019) a média pluviométrica anual maior que a região do semiárido nordestino é uma peculiaridade dos brejos de altitude.

Ainda neste aspecto ambiental Medeiros et al. (2017) afirmam que suas formações florestais são disjunções de floresta atlântica, ilhadas pela vegetação da Caatinga uma característica indicadora de grande biodiversidade. Assim é observado que as áreas de brejo de altitude apresentam um grande potencial no que diz respeito à diversidade da flora e fauna, o que condiz com a teoria dos refúgios (MARQUES et al., 2014). Para Medeiros (2016) no que diz respeito as áreas de exceção estes ambientes de brejos de altitude funcionam como áreas de refúgio em meio a realidade dos sertões graças a interação entre clima, solo, rochas, formas e cobertura da terra. Essa realidade pode ser encontrada em Santos (2014) quando afirma que essas áreas de exceção são capazes de proporcionar condições ambientais para que representações de outros biomas se desenvolvam no domínio das caatingas, como é o caso de manchas de cerrado e floresta Atlântica. Desta forma, a principal característica de um brejo de altitude está relacionada a uma área definida como ilha ou enclave com expressões específicas e diferenciadas do meio onde estão inseridas (MEDEIROS et al., 2018).

Devido a diferentes tipos de atividades econômicas realizadas na Mata Atlântica e em seus ecossistemas associados como os brejos de altitude, é observado intenso processo de desmatamento e transformação do ambiente (VIANA et al., 1997). A agricultura de subsistência e até mesmo a pecuária de corte vem tomando o lugar da vegetação nativa e, para os brejos de altitude isso torna-se mais evidente, já que são aproveitados a maior frequência de chuvas no ambiente para obter melhor rendimento de recursos econômicos (LINS, 1989). Botelho (2019) ao estudar o desenvolvimento da cana de açúcar em região de brejo de altitude na Paraíba concluiu que uma variedade se sobressaia em relação a outras cultivares analisados apontando um potencial econômico da mesma na região.

Segundo Santos et al. (2019) em decorrência da apropriação e utilização desordenada dos recursos naturais, os brejos de altitude tornam-se alvos de intensa exploração. Perda de hábitat, fragmentação, caça, coleta seletiva de plantas e animais e, consequentemente, perda de diversidade biológica, é o cenário atual nos brejos de altitude no Nordeste do Brasil, os quais poderão desaparecer completamente (TABARELLI et al., 2004). Nesse sentido, a diminuição da biodiversidade especialmente no estado de Pernambuco/PE, onde 
o desmatamento do bioma Caatinga é muito alto (SILVEIRA et al., 2003; SANTOS et al., 2008; PEREIRA et al., 2014), atrelado ao isolamento natural dos brejos de altitude, demandam a elaboração de políticas públicas em torno de modelos sustentáveis de exploração, manejo, preservação e reflorestamento (MARQUES et al., 2014).

Segundo Medeiros et al. (2016) as condições climáticas bastante favoráveis à agricultura, fazem dos brejos de altitude áreas prioritárias de ocupação e desenvolvimento de atividades de pecuaristas e agricultores. Laurentino et al. (2011) analisando uma região de brejo de altitude no interior de Pernambuco e aplicando os índices NDVI (Normalized Difference Vegetation Index) e EVI (Enhanced Vegetation Index) a fim de comparar as sensibilidades entre eles concluiu que as áreas de brejo de altitude, apresentam um grande potencial no que diz respeito à diversidade da vegetação quando encontrado as manchas de cerrado, a caatinga hipoxerofila e vegetação de mata atlântica. Outro aspecto interessante, segundo Ferreira (2018), ocorre nessa região de Pernambuco, onde há pouca demanda de uso águas subterrâneas, concentrada sobretudo, na borda do atlântico, regiões de Brejos de Altitudes como, Serra dos Cavalos, Serra do Bitury e Triunfo entre várias outras, e que isto implica na capacidade de oferta de água subterrânea, principalmente nos longos períodos de estiagens. Já no âmbito dos microorganismos os fungos, por exemplo, o Brejo de Altitude, a Caatinga e a Mata Atlântica apresentam aglomerados filogenéticos e as comunidades de liquens da Caatinga e dos Brejos de altitude são filogeneticamente mais próximas (NASCIMENTO, 2017).

Neste cenário de diferenças significativas as formas de produção podem contribuir para processos de preservação ou de degradação ambiental. Práticas como plantio em curvas de nível e rotação de culturas, por exemplo, podem fortalecer os agroecossistemas e proteger os solos. Já a intensificação de tecnologia, a mecanização e a monocultura podem provocar erosões, lixiviação e crescente impacto ambiental negativo. Segundo Ribeiro et al. (2016) a erosão é uma das principais preocupações na busca pelo desenvolvimento sustentável e pela conservação da capacidade produtiva de uma região porque ela pode comprometer o transporte de nutrientes, provocando perda de matéria orgânica e exigir grandes concentrações defensivos agrícolas, causando dificuldades na relação de troca de energias dos solos e plantas. Silva et al. (2019) ao analisar a estrutura da taxocenose de térmitas em duas áreas de Brejo de Altitude concluiu que essa região está, atualmente, sob alta pressão ecológica e necessitam de preservação.

Ainda segundo Ribeiro et al. (2016) cerca de 1,5 bilhões de hectares (10\% da superfície terrestre), já foram irreversivelmente degradados pelos processos de erosivos. Sabe-se, porém que grade parte desse processo erosivo está diretamente ligado as práticas e manejo agropecuários. Esse valor do impacto ambiental não é contabilizado e tão pouco remunerado em termos de economia de modo geral. Faltam subsídios e atenção para que esse impacto seja dimensionado. Com o aumento da população e a necessidade de mais produção e alimentos, principalmente, é preciso estar mais atento para essa relação produção $x$ impacto ambiental. Neste sentido, o trabalho objetiva entender como as alterações causadas no ambiente para a obtenção de recursos econômicos refletem tanto no crescimento econômico quanto na climatologia. 


\section{MATERIAIS E MÉTODOS}

\section{Área de estudo}

A floresta atlântica brasileira, segundo Cardoso (2011), é composta por grande diversidade ambiental. No que diz respeito a região nordeste e a biodiversidade existente nela destacam-se os brejos de altitude, presentes em serras e planaltos do semiárido, que devido ao relevo apresenta um microclima diferenciado para a região (TAVARES et al., 2000; LIMA, 1982). São, em síntese, ilhas de floresta úmidas, cercada por vegetação de caatinga (CARDOSO, 2012). Encontram-se mais precisamente nos estados de Pernambuco, Paraíba, Rio Grande do Norte e Ceará (LIMA, 1982).

No caso do agreste de Pernambuco e Paraíba é conhecida como 'agreste subúmido' e definida como formações com microclima diferenciado, onde, por efeito orográfico, a pluviosidade é bastante superior à do entorno. Em Pernambuco, segundo Lima (1960), são especificidades da floresta tropical da caatinga localizadas, geralmente, em serras sejam graníticas ou cretáceas acima de 500m até aproximados $1100 \mathrm{~m}$. No ano de 1971, de acordo com Vasconcelos Sobrinho (1971), a área total de brejos de altitude do estado de Pernambuco era de $4.850 \mathrm{~km}^{2}$ e compreendiam 21,97\% do total de brejos de altitude identificados no Brasil.

Garanhuns é uma cidade do Agreste Meridional de Pernambuco (Figura 1) com área de $472.461 \mathrm{Km}^{2}$ e população estimada de 139 mil habitantes. Com PIB per capita de 15.200, 55, a economia da cidade é baseada na Agropecuária, Turismo, comércio e prestação de serviços, sendo considerada um município com área estratégica para manter um suporte em relação aos municípios que os circundam.

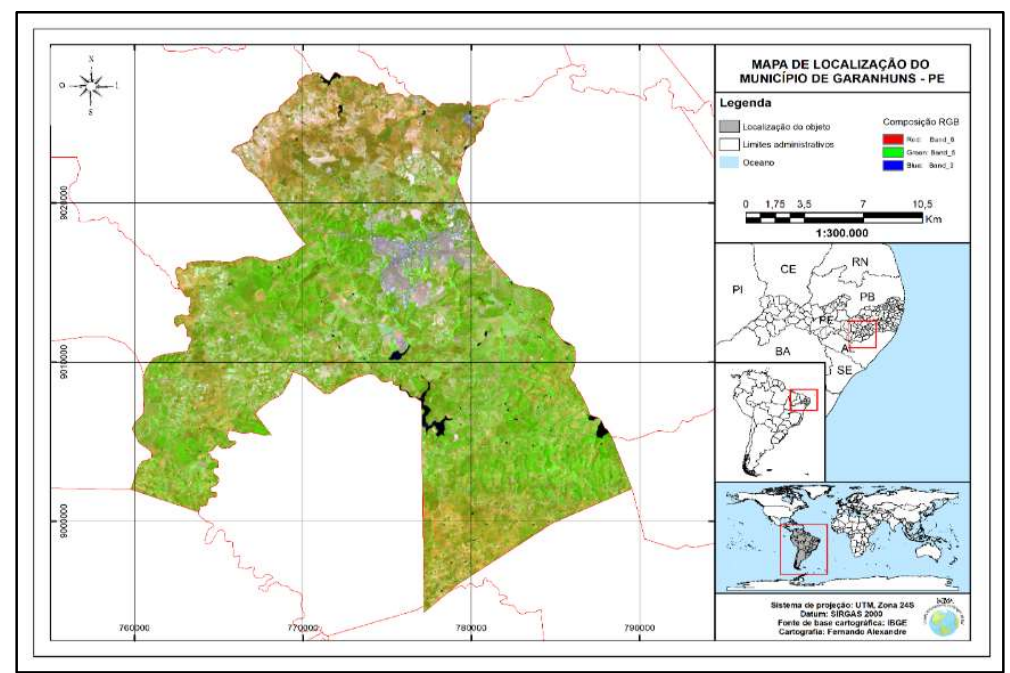

Figura 1: Mapa de localização do Município de Garanhuns.

\section{Coleta e análise de dados}

A pesquisa qualitativa e exploratória foi uma opção por permitir a análise de aspectos subjetivos da ação social, estimulando a compreensão sobre alguns fenômenos sociais que ocorrem a partir das condições naturais (HAGUETTE, 2007; GIL, 2008). Abre-se, aqui, a oportunidade para entender uma determinada realidade para além daquilo que se apresenta. A pesquisa bibliográfica foi o primeiro passo nesta pesquisa.

A característica da pesquisa exploratória citada por Gil (2008) possibilitar as condições de explicitar 
com maior clareza a natureza do problema estudado e uma de suas principais ferramentas é o levantamento bibliográfico podendo contar também com entrevistas com pessoas experientes no problema pesquisado. A pesquisa bibliográfica é um aglutinado de vários estudos torno de um determinado tema que são importantes por conseguirem fornecer informações relevantes para a compreensão de determinada temática. Ela abrange: publicações avulsas, livros, jornais, revistas, vídeos, internet, etc. Esse levantamento inicial serve/podem subsidiar tanto nos estudos baseados em dados originais, colhidos numa pesquisa de campo, bem como aqueles inteiramente baseados em documentos. Segundo GIL, Marconi e Lakatos:

A pesquisa documental é muito próxima a pesquisa bibliográfica. A diferença está na natureza das fontes primárias (manuscritas ou não), pois vale-se de materiais que ainda não receberam um tratamento analítico ou que, ainda, podem ser reelaborados de acordo com a problemática da pesquisa. Os documentos primários podem ser obtidos em: arquivos, igrejas, sindicatos, instituições de pesquisa etc.). (GIL, 2008; MARCONI et al., 2007)

Para este trabalho utilizou-se além de uma revisão de literatura, análise de documentos e dados de Índice de Vegetação da Diferença Normalizada (NDVI). Análise proposta por Rouse et al. (1973), que visa normalizar o resultado do Índice da Razão Simples, entre um intervalo de -1 a +1, é a razão entre a diferença pela soma das bandas do infravermelho e vermelho, segundo a equação abaixo. Sendo -1 para alvos terrestres e +1 para alvos no limite superior, gerando uma imagem com 256 tons de cinza, os tons de cinza variam mais claros estão relacionados a valores mais elevados do NDVI, enquanto que os mais escuros com valores menores. É amplamente utilizado para geração de perfis sazonais e temporais da vegetação, visando detectar atividades sazonais e fonológicas durante o período de crescimento (PONZONI et al., 2012). Um dos déficits do NDVI é que ele leva em consideração a refletância do solo e fatores de declividade, o que poderá dar resultados não fidedignos com a realidade (VIGANÓ et al., 2011). Usando a equação:

$$
\text { NDVI: } \frac{\mathrm{B} 5-\mathrm{B} 3}{\mathrm{~B} 5+}(2)
$$

Desta forma a pesquisa esteve fundamentada, prioritariamente, nas publicações de dados do Instituto Brasileiro de Geografia e Estatística (IBGE), Agência Pernambucana de Águas e Clima (APAC) e Instituto Nacional de Meteorologia (INMET). Para o IBGE, foram coletados dados de área de lavoura permanentes e temporárias, pastagens naturais, plantadas em boas e em más condições e matas ou florestas naturais, destinadas a preservação permanente ou reserva legal e florestas plantadas.

Posteriormente, os dados de produção e pluviosidade foram relacionados através do uso de gráficos de linhas estabelecendo independência entre os eixos relacionados para avaliar o controle de utilização dos solos na agricultura e pecuária mediante os índices pluviométricos da série histórica em questão.

\section{RESULTADOS}

\section{Histórico de uso do solo}

A relação crescimento econômico e meio ambiente apresenta contrastes que podem ser facilmente visualizados quando observados a destinação do uso de terras nos municípios brasileiros. No caso de Garanhuns, agreste pernambucano, a área total de estabelecimentos rurais no município segundo o IBGE em 2017 é de 24.429,247 hectares e são utilizadas de acordo com a tabela 1. 
Tabela 1: Distribuição de estabelecimentos rurais mediante o formato de uso da terra no município de Garanhuns/PE em 2017 (IBGE, 2019).

\begin{tabular}{|c|c|c|}
\hline \multicolumn{2}{|l|}{ Utilização das terras } & $\begin{array}{l}\text { Área Ocupada } \\
\text { (ha) }\end{array}$ \\
\hline \multirow{3}{*}{ Lavouras } & Permanentes & 715,116 \\
\hline & Temporárias & $4.576,825$ \\
\hline & Cultivo de flores & 9,291 \\
\hline \multirow{3}{*}{ Pastagens } & Naturais & $4.636,337$ \\
\hline & Plantadas em boas condições & $6.154,481$ \\
\hline & Plantadas em más condições & $5.578,976$ \\
\hline \multirow{3}{*}{ Matas ou Florestas } & Naturais & 163,200 \\
\hline & Naturais destinadas a preservação permanente ou reserva & $1.159,117$ \\
\hline & Florestas Plantadas & 15,250 \\
\hline Sistemas Agroflorestais & $\begin{array}{l}\text { Área cultivada com espécies florestais também usada para lavouras e pastejo } \\
\text { por animais }\end{array}$ & $1.417,360$ \\
\hline $\begin{array}{l}\text { Sistemas de preparo de } \\
\text { solo }\end{array}$ & Plantio direto na palha & 3,294 \\
\hline
\end{tabular}

Como observado as áreas de lavoura e pastagem representam $82,68 \%$ do total de áreas dos estabelecimentos rurais do município. Em contraponto, as regiões de mata ou florestas são limitadas a 5,01\% ha da área total observada. Os dados são melhor demonstrados na figura 2, onde observa-se o uso do solo segundo a sua cobertura vegetal. Na figura, percebe-se a existência de um grande quantitativo de vegetação rasteira, relacionada a áreas de pastagem e campos.

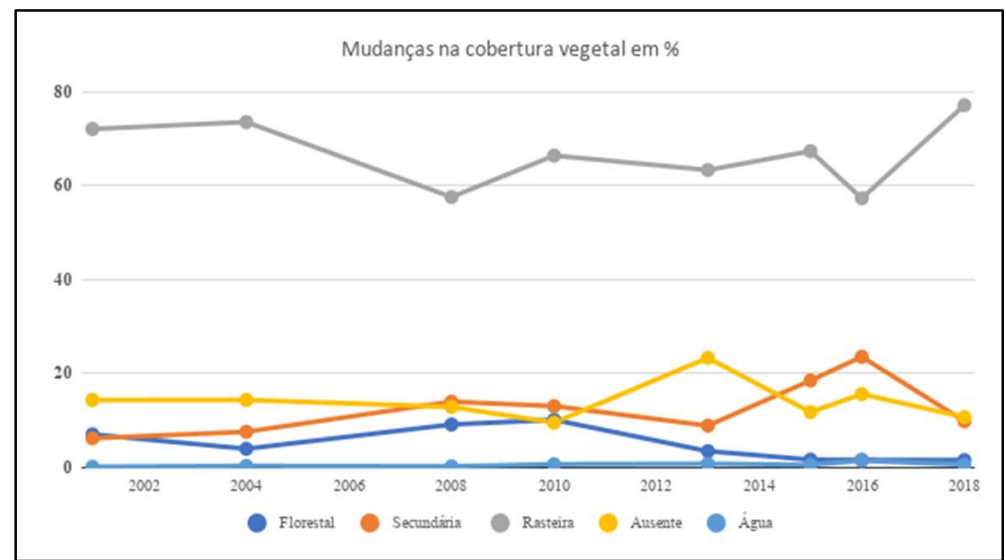

Figura 2: Mudanças na cobertura vegetal ao longo da série histórica de 2000 à 2018 no município de Garanhuns, Pernambuco.

Outro ponto observado é que o ano de 2012 foi limitante na modificação do uso do solo, onde são percebidos o crescimento de áreas com ausência de vegetação e uma redução significativa das áreas florestais (Figura 4). Em contrapartida, as áreas de vegetação secundária, a partir deste ano cresceram significativamente.

Esse cenário justifica o que se pôde observar da tabela 1 e figuras 2,3 e 4 é que a maior parte das terras férteis e em condições de uso foram ocupadas pela agropecuária restando um mínimo de áreas naturais ou secundárias e, mesmo assim, essas áreas estariam no entorno de zonas de vales ou em regiões acentuadamente inclinadas (Figura 5). 


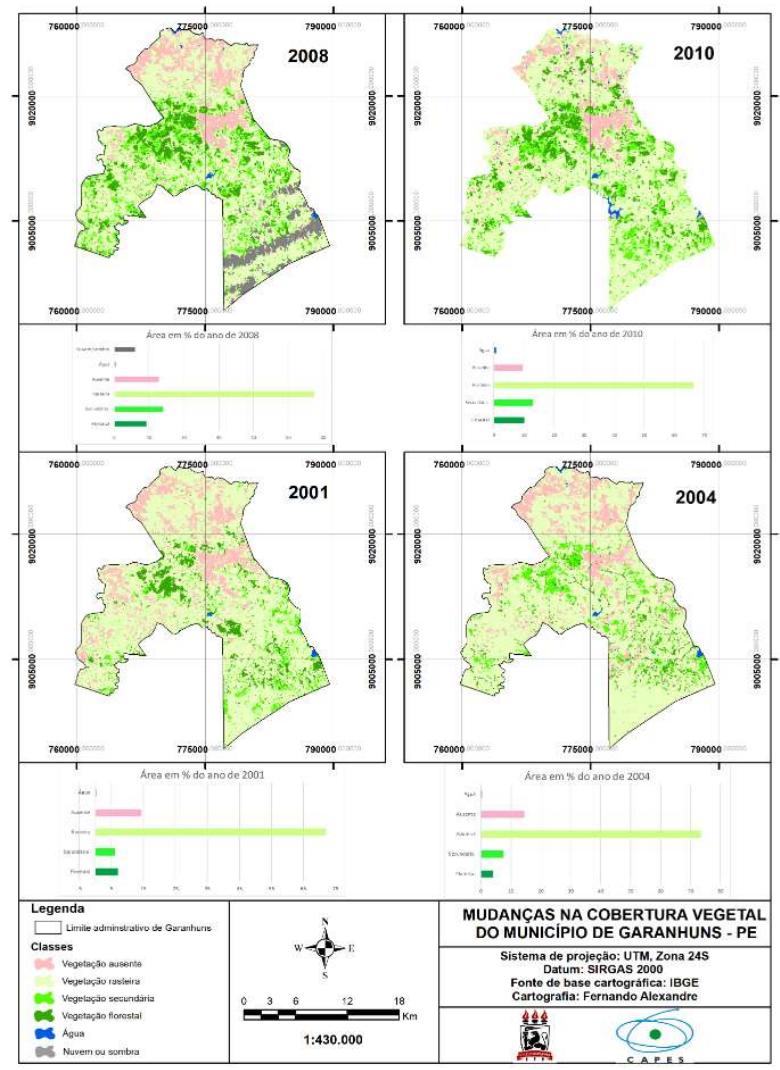

Figura 3: Histórico de mudanças na cobertura vegetal entre os anos de 2001 à 2010 do município de Garanhuns, Pernambuco.

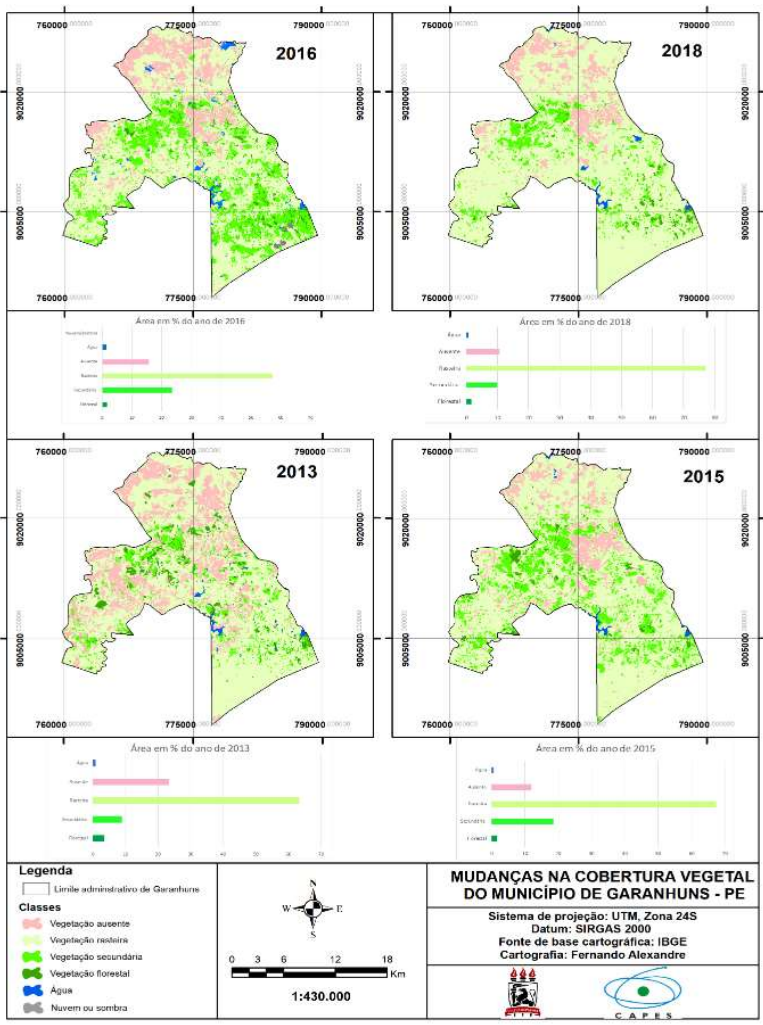

Figura 4: Histórico de mudanças na cobertura vegetal entre os anos de 2013 à 2018 do município de Garanhuns, Pernambuco.

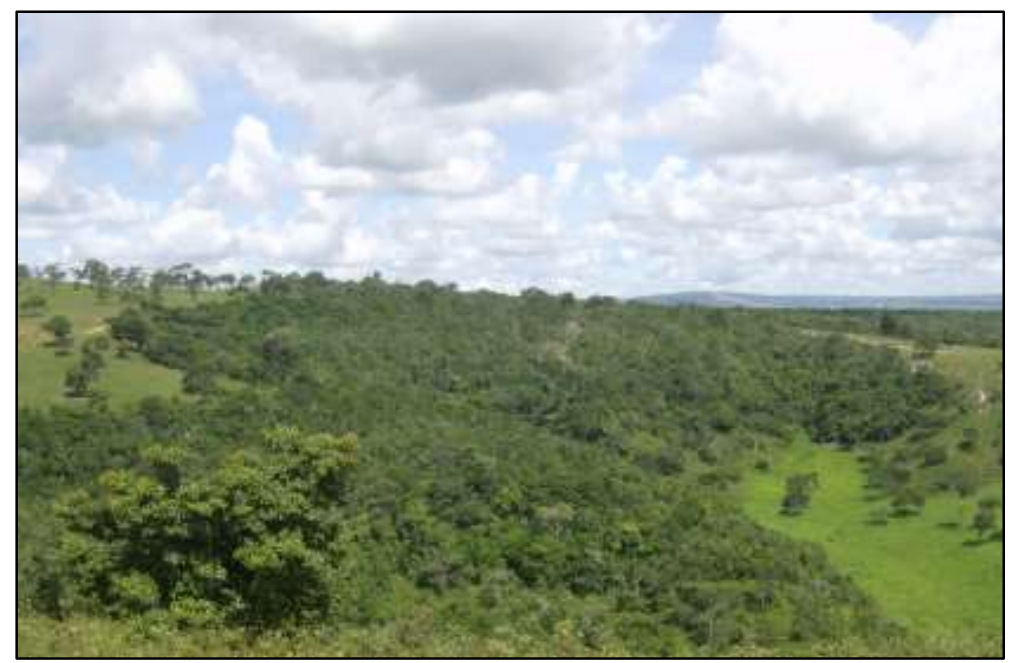

Figura 5: Fragmento de área natural no município de Garanhuns, Pernambuco

\section{Relação da produção agropecuária com a precipitação da região}

O milho e o feijão são culturas de ciclo curto comercializadas na região como práticas culturais de pequenos e médios agricultores da região reproduzindo a característica da região nordeste de produção alimentícia em propriedades desse porte. Para o ano de 2018, a tabela 2 mostra o quantitativo de produção em destaque alcançados no município de Garanhuns nas principais culturas. 
Tabela 2: Quantitativo de produção das terras destinadas à lavoura e pastagem em 2018 no município de Garanhuns/PE.

\begin{tabular}{|l|l|l|}
\hline Utilização das terras & Produção & Quantitativo \\
\hline \multirow{4}{*}{ Lavouras } & Banana & $80 \mathrm{t}$ \\
\cline { 2 - 3 } & Mandioca & $4.000 \mathrm{t}$ \\
\cline { 2 - 3 } & Milho & $2.000 \mathrm{t}$ \\
\cline { 2 - 3 } & Feijão & $968 \mathrm{t}$ \\
\hline Pastagens & Bovino (Leite e Corte) & 22.254 cabeças \\
\hline
\end{tabular}

Nos últimos 30 anos, Garanhuns possui uma média de precipitação anual de 777 mm de chuva. As médias de precipitação mensais (Figura 6) mostram que os índices de chuva não são constantes e apresentam maior intensidade entre os meses de maio a julho, época na qual ocorre o plantio de lavouras temporárias como o milho e o feijão. No período chuvoso, as médias de precipitação mensal chegam a aproximadamente $135 \mathrm{~mm}$ no mês de maior intensidade chuvosa como é observado na figura 6.

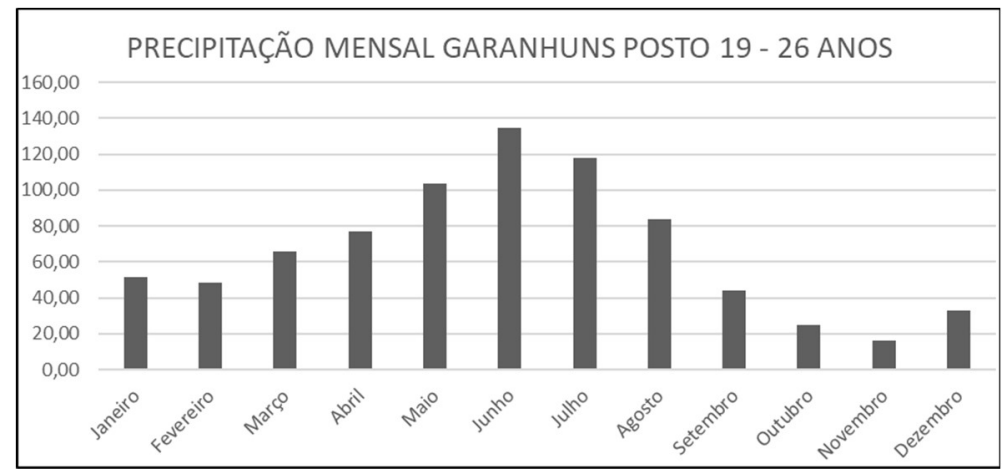

Figura 6: Médias de precipitação mensal dos últimos 30 anos para o município de Garanhuns, Pernambuco.

Para o município de Garanhuns, o ano com menores índices de precipitação foi o ano de 2012 (Figura 7) com cerca de $450 \mathrm{~mm}^{2}$ durante todo o ano. Isto é uma redução para a média climatológica da região de $42 \%$, levando em consideração a climatologia dos últimos 25 anos.

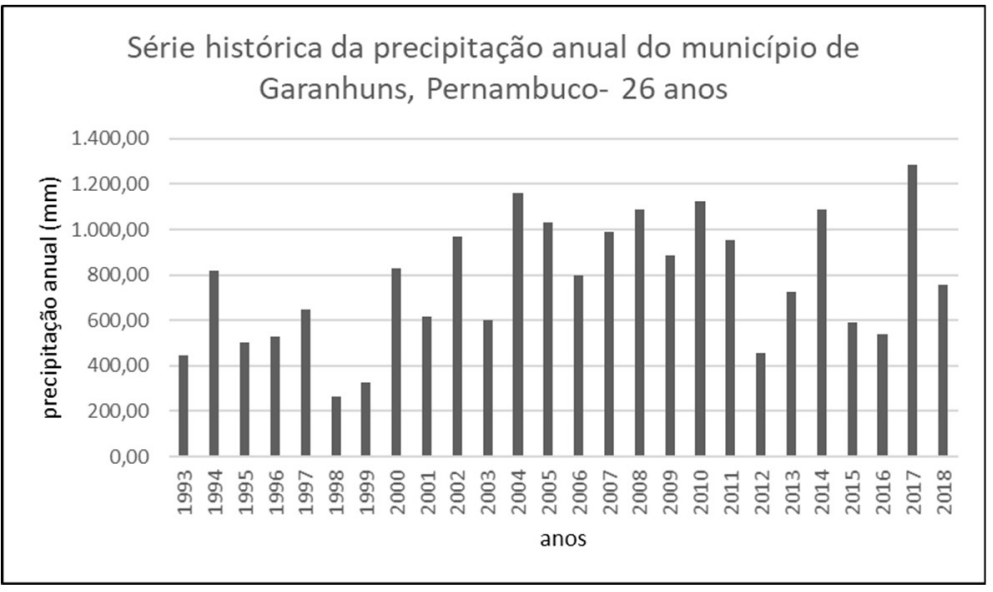

Figura 7: Precipitação anual do período de 1993 até 2018 do município de Garanhuns, Pernambuco.

A partir dos dados de obtenção da produção agropecuária no município de Garanhuns para o ano de 2018, pôde-se observar as séries históricas de algumas culturas que são tradicionais na região e outras que estão em ascensão relacionadas as séries históricas dos dados pluviométricos. A primeira das culturas permanente é a banana (Figura 8) onde se observam uma redução significativa da produção desde o ano de 2010, podendo ser vinculada a escassez de recursos hídricos e a seca de 2012. Para os Cultivos de Mandioca (Figura 9), o ano de 2012, considerado um ano com acentuado déficit hídrico para a região, foi o que mais 
rendeu produção do cultivo. Porém os efeitos posteriores também fizeram com que a produção fosse reduzida ao longo dos anos.

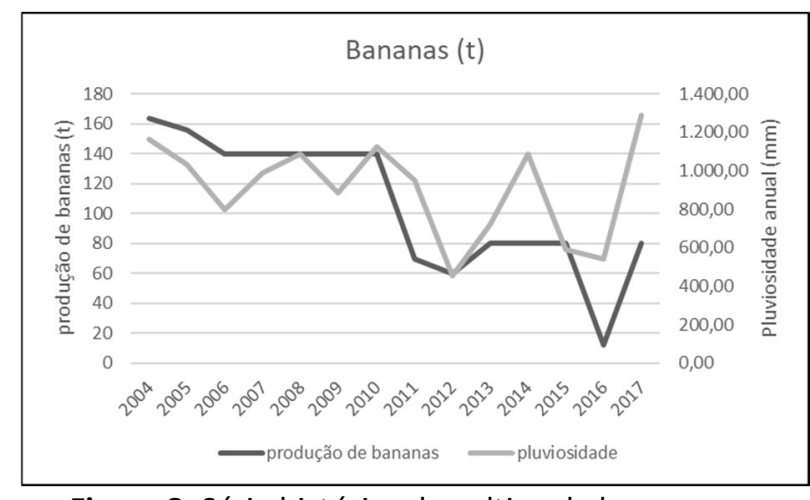

Figura 8: Série histórica do cultivo de bananas no município de Garanhuns, Pernambuco.

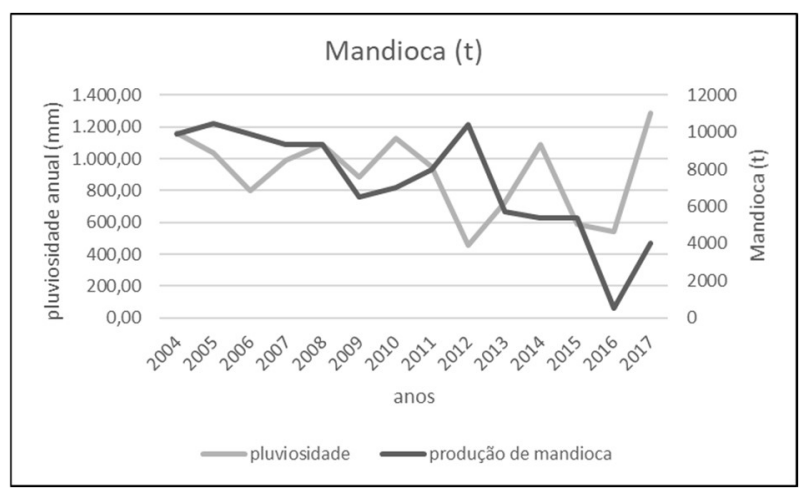

Figura 9: Série histórica do cultivo de mandioca no município de Garanhuns, Pernambuco.

Para os Cultivos de feijão (Figura 10), a região passou por um processo de redução na produção de 400 toneladas, oscilando anualmente os quantitativos de produção vinculados sempre a perda de produção. Pode-se observar na figura 10 que a cultura do feijão está diretamente ligada aos índices pluviométricos do local.

Para a produção de milho (Figura 11), o quantitativo da série histórica sempre foi reduzido, não chegando a 600 toneladas de produção anual. Porém, no ano de 2017, houve um crescimento significativo da produção com aumento de mais de $300 \%$ da mesma. Este fator pode estar associado aos índices de produção animal e a resiliência dos produtores da região para com o longo período de seca percorrido entre os anos de 2012 até 2016. Muitas das atividades da pecuária da região foram voltadas ao confinamento de animais, sendo demandadas uma quantidade maior de insumos na alimentação das criações.

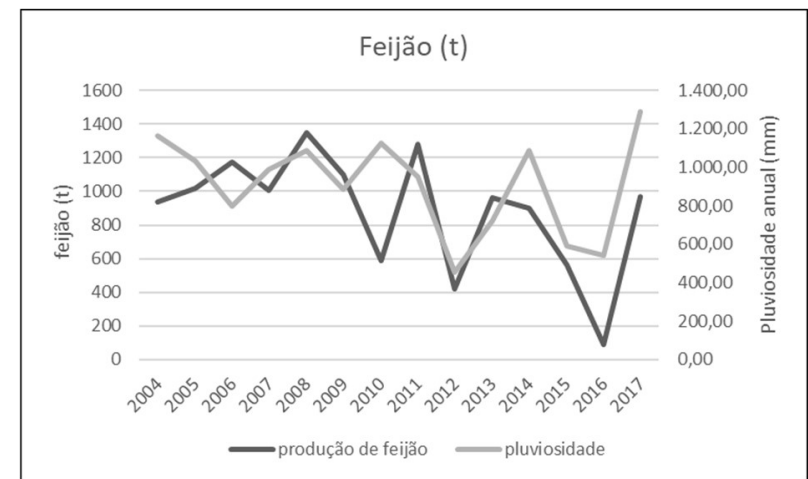

Figura 10: Série histórica do cultivo de feijão no município de Garanhuns, Pernambuco.

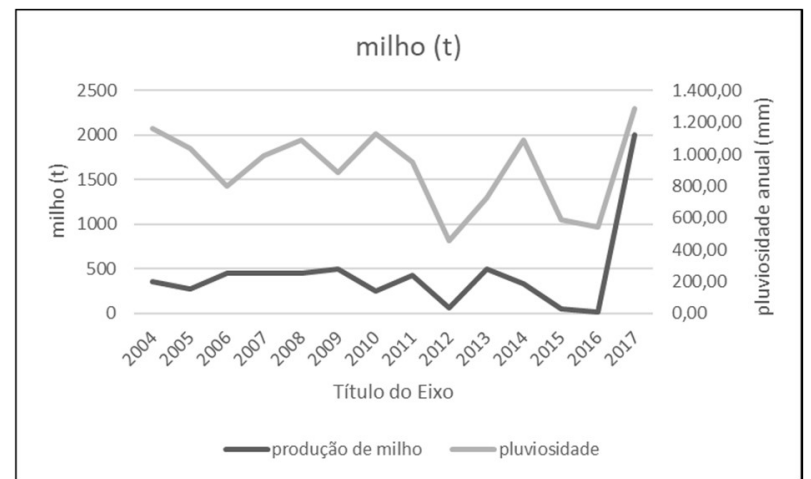

Figura 11: Série histórica do cultivo de milho no município de Garanhuns, Pernambuco.

Um dado interessante a ser observado está relacionado está para a produção agrícola das culturas citadas no ano de 2016, onde as culturas sofreram uma redução significativa da sua produção. No que diz respeito ao período chuvoso deste ano, são observados que grande parte da precipitação foi condensada em um mês (Figura 12) e o período em que ocorrem o plantio e colheita das culturas temporárias houve uma redução da pluviosidade média (Figura 6) para esta região.

Vale salientar que os períodos de 2012 e 2016 foram os períodos em que as culturas, sejam 
temporárias como também as permanentes, tiveram uma redução significativa na produção, podendo ser vinculados aos quantitativos de pluviosidade da região (figura 6) que para os dois anos tiveram índices de precipitação anual menores que $600 \mathrm{~mm}$. Em toda a série histórica dos dados pluviométricos, só pode-se observar tal efeito na seca de 1998. O fator a ser levado em consideração para tais fenômenos, é que os processos de produção, neste caso, agrícola estão sendo suprimidos. Porém, as regiões voltadas a agricultura ainda mantêm os seus índices de território e as áreas naturais se limitando a uma porcentagem muito reduzida do território rural total (Tabela 1 ).

Para a produção pecuária, podem-se observar os dados históricos das culturas tradicionais e das que estão em ascensão na região. Para o efetivo bovino (Figura 13), a produção dos últimos 15 anos teve seu pico de produção no ano de 2010 com 40 mil cabeças de gado. Após este período, o efetivo entrou em declínio com maior redução do rebanho entre os anos de 2012 e 2013 em que foram para 22 mil cabeças de gado.

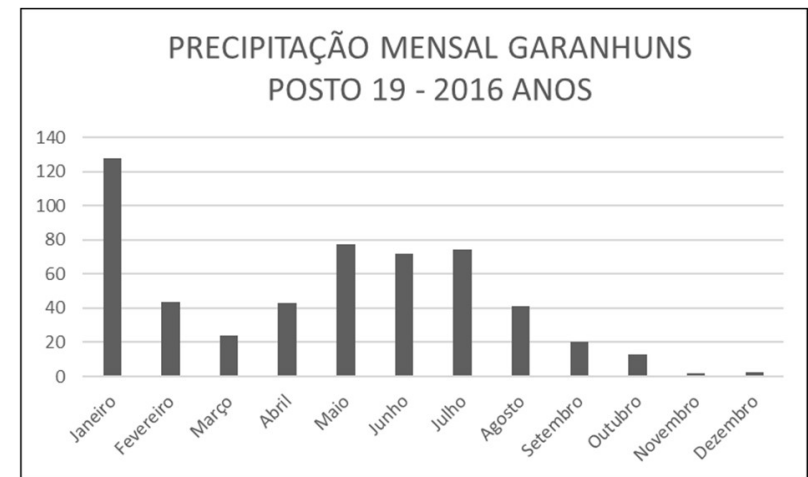

Figura 12: Médias de precipitação mensal para o ano de 2016 no município de Garanhuns, Pernambuco.

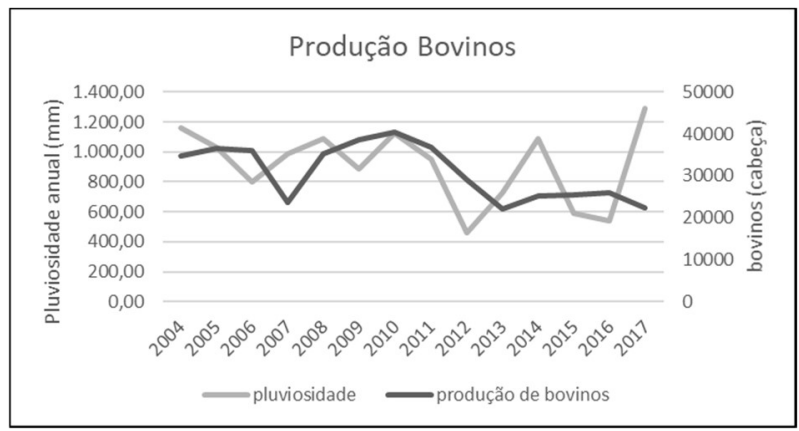

Figura 13: Série histórica do efetivo de rebanho bovino no município de Garanhuns, Pernambuco.

Para a cultura de Galináceos e Suínos (Figura 14 e 15), os índices mostram uma cultura em ascenção que pode ser vínculada a três fatores principais que são a reduzida área para criação, que basicamente é limitada a um galpão, o seu rápido retorno financeiro e a instalação de empresas para o escoamento da produção na região, possibilitando com que o produtor tenha facilidade na compra de ração e na venda do produto para abatimento.

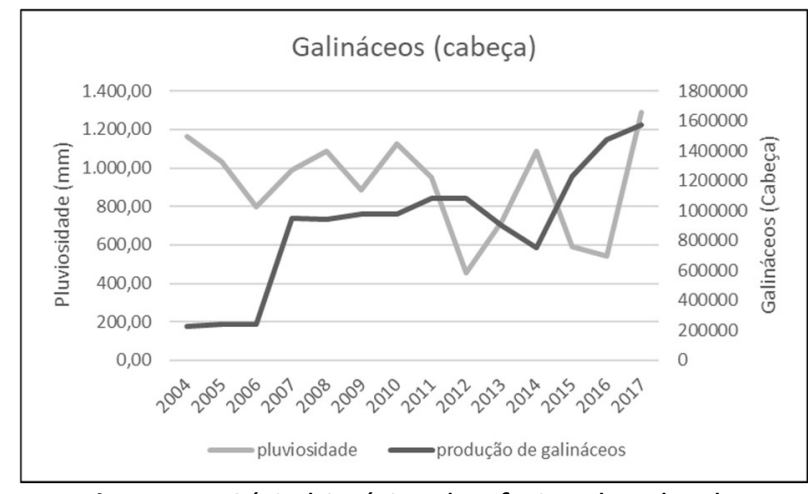

Figura 14: Série histórica do efetivo de rebanho galináceo no município de Garanhuns, Pernambuco.

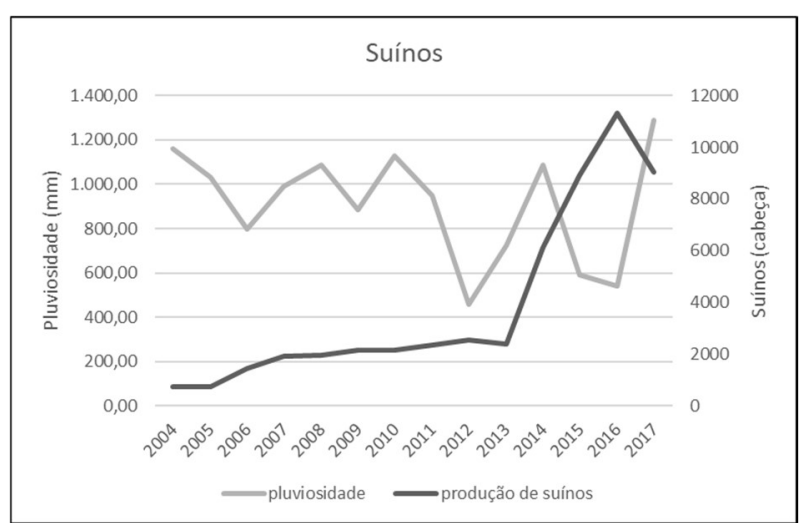

Figura 15: Série histórica do efetivo de rebanho suíno no município de Garanhuns, Pernambuco. 


\section{DISCUSSÃO}

\section{Histórico de uso do solo}

No Brasil o avanço da produção agropecuária se reflete na conversão de florestas em pastagens e cultivos (ALBUQUERQUE et al., 2002). A relação crescimento econômico e meio ambiente apresenta contrastes que podem ser facilmente visualizados quando observados a destinação do uso de terras nos municípios brasileiros. No caso de Garanhuns, agreste pernambucano, a área total de estabelecimentos rurais no município segundo o IBGE em 2017 é de 24.429,247 hectares e são utilizadas de acordo com a tabela 1.

Como observado as áreas de lavoura e pastagem representam $82,68 \%$ do total de áreas dos estabelecimentos rurais do município. Em contraponto, as regiões de mata ou florestas são limitadas a 5,01\% ha da área total observada. Pode-se relacionar tal fator de uso do solo na região com o tipo de solo e níveis de precipitação das áreas de brejo de altitude (TABARELLI et al., 2004) como é o caso do município de Garanhuns. Como tais áreas estão em uma região onde a altitude é de aproximadamente $800 \mathrm{~m}^{2}$ possuem temperaturas mais amenas, junto dos níveis de precipitação que são maiores. Isso contribui no processo de formação do solo e auxilia na decomposição de matéria orgânica, deixando os solos mais férteis (VON LUTZOW et al., 2009).

$\mathrm{Na}$ figura 2, observa-se o uso do solo segundo a sua cobertura vegetal. Nela, percebe-se a existência de um grande quantitativo de vegetação rasteira, relacionada a áreas de pastagem e campos. Um fato a ser observado é a redução significativa das regiões florestais para uso do solo em agricultura ou pecuária. Outro ponto observado é que o ano de 2012 foi limitante na modificação do uso do solo, onde são percebidos o crescimento de áreas com ausência de vegetação e uma redução significativa das áreas florestais (Figura 4). Em contrapartida, as áreas de vegetação secundária, a partir deste ano cresceram significativamente.

Este fato é explicado pelo estresse hídrico causado pela seca de 2012-2015 (MARENGO et al., 2016), onde muitas áreas antes cobertas por vegetação rasteira passaram por um processo de degradação, levando a ausência de vegetação e consequente desuso da terra, dando espaço ao crescimento e ocupação de vegetação secundária (Figuras 3 e 4).

A produção agrícola dessa região é baseada, principalmente, numa economia de subsistência através do cultivo de feijão, milho, mandioca, e de algumas frutíferas como a banana já que Pernambuco ocupa posição de destaque produtivo no ranking nacional. O milho e o feijão são parte principal do cardápio do Brasil enquanto a banana é a fruta de maior consumo mundial depois dos cítricos, fazendo-se presente na dieta das diferentes camadas sociais, seja pela sua importância nutritiva, seja em função do seu preço acessível ao público consumidor e, sobretudo, pelo seu sabor. Já a mandioca é extremamente relevante na alimentação do Nordeste. No Brasil, o consumo é de $34,5 \mathrm{~kg} / \mathrm{hab} / \mathrm{ano}$, confirmando a elevada demanda do mercado doméstico pelo produto (DANTAS et al., 1997; MATSUURA et al., 2004). Esses alimentos são parte fundamental do cardápio no nordeste brasileiro e importantes elementos da economia doméstica o que culmina na sua presença constante na lei de oferta e procura do mercado. Apesar disso, com a situação 
hídrica da região, em períodos de estiagem, a demanda alimentar humana e animal não consegue ser atendida localmente sendo necessário práticas de estocagem, suporte forrageiro e aumento do poder de compra de produtos oriundos de outras regiões (SANTOS et al., 2011).

\section{Relação da produção agropecuária com a precipitação da região}

É considerável dizer que entre as produções agrícolas desenvolvidas no município de Garanhuns, destacam-se os cultivos temporário como a mandioca que é uma das principais culturas trabalhadas da região e tem como mecanismo de escoamento a produção de farinha de mandioca (BARROS JUNIOR et al., 2016) e o seu uso na alimentação animal da própria região (CARDOSO, 2012). 0 milho e o feijão são culturas de ciclo curto comercializadas na região como práticas culturais de pequenos e médios agricultores da região reproduzindo a característica da região nordeste de produção alimentícia em propriedades desse porte.

No que desrespeito a precipitação anual, o município de Garanhuns, assim como todo o Nordeste, passou por um período de seca intensa entre os anos de 2012 e 2015 (MARTINS et al., 2015). Porém, para o município de Garanhuns, o ano com menores índices de precipitação foi o ano de 2012 (Figura 7) com cerca de $450 \mathrm{~mm}^{2}$ durante todo o ano. Isto é uma redução para a média climatológica da região de $42 \%$, levando em consideração a climatologia dos últimos 25 anos.

A primeira das culturas permanente é a banana (Figura 8) onde se observam uma redução significativa da produção desde o ano de 2010, podendo ser vinculada a escassez de recursos hídricos e a seca de 2012. Tais fatores reduziu a produção em 50\% e acompanham os índices pluviométricos da região, observando que a sua produção está vinculada a quantidade hídrica oferecida pela região (PINO et al., 2000).

Para os Cultivos de Mandioca (Figura 9), o ano de 2012, considerado um ano com acentuado déficit hídrico para a região, foi o que mais rendeu produção do cultivo. Porém os efeitos posteriores também fizeram com que a produção fosse reduzida ao longo dos anos. Tais fatores estão vinculados a tolerância da espécie para com ambientes secos e resistência a variação dos solos e clima (LORENZI, 2002). Neste Período, grande parte da produção esteve voltada para atender à necessidade da pecuária bovina da região e, consequentemente, atingiu os maiores preços, gerando um interesse por parte dos produtores da cultura agrícola.

Pode-se observar na figura 10 que a cultura do feijão está diretamente ligada aos índices pluviométricos do local. O plantio temporário do feijão está associado ao período mais chuvoso da região que acontece entre os meses de maio a agosto (Figura 6), sua produção está ligada a oferta de água e micronutrientes do solo (FAGERIA et al., 2004).

Um dado interessante a ser observado está relacionado está para a produção agrícola das culturas citadas no ano de 2016, onde as culturas sofreram uma redução significativa da sua produção. No que diz respeito ao período chuvoso deste ano, são observados que grande parte da precipitação foi condensada em um mês (Figura 12) e o período em que ocorrem o plantio e colheita das culturas temporárias houve uma redução da pluviosidade média (Figura 6) para esta região, afirmando a ideia de que nas produções, como a de feijão, são indispensáveis a disponibilidade de água para o sucesso da produção (FAGERIA et al., 2004). 
Para a produção pecuária, podem-se observar os dados históricos das culturas tradicionais e das que estão em ascensão na região.

Para o efetivo bovino (Figura 13), a produção dos últimos 15 anos teve seu pico de produção no ano de 2010 com 40 mil cabeças de gado. Após este período, o efetivo entrou em declínio com maior redução do rebanho entre os anos de 2012 e 2013 em que foram para 22 mil cabeças de gado. Tal saldo pode ser refletido com os períodos da seca de 2012 (MARENGO et al., 2016), onde parte do rebanho foi a óbito ou escoado para outras regiões. Para o ano de 2017, o quantitativo do rebanho foi de 22 mil cabeças de gado com redução de quase $50 \%$ de sua produção. Levando em consideração que as áreas de pastagem ocupam boa parte das áreas rurais do município, um efeito observado com a redução da produção bovina consecutivo aos anos 2012 foi o aumento das áreas de vegetações secundárias (Figuras 2, 3 e 4) pela falta de uso do solo. É observável que a linha de crescimento da produção de bovinos segue o ritmo da pluviosidade da região, já que a produção reflete basicamente no quantitativo de oferta de pasto e outros subsídios da localidade (ZENS, 2008).

São observadas na figuras 14 e 15, que as produções de suínos e galináceos não geram influência significativa com o histórico pluviométrico da região, já os animais são armazenados em confinamento para engorda (FRANÇA et al., 2007) , sem a direta necessidade de pluviosidade regular para a obtenção de bons resultados na produção.

As alternativas de cultura mudam mediante as exigências do mercado e a sua perspectiva e possibilidades de produção. $\mathrm{O}$ que podasse observar é que o quantitativo de produções tradicionais que modificaram o ambiente do município ao longo de muitos anos gerou um fluxo de saturação elevado a ponto de reduzir significativamente o potencial de produção e, consequentemente impactar ainda mais o ambiente. É bem verdade que as áreas de pastagens e lavouras se mantêm com produção reduzida, o que aumenta ainda mais o impacto causado aquele ambiente. $O$ fato é que a preocupação ambiental ainda não é um fator que preocupa produtor e consumidor pelo motivo de ainda não estar causando impactos tão severos a população. Uma saída seria a produção agroecológica, ou até mesmo a inclusão das ideias de economia ambiental. A inserção de uma experiência mesmo que pontual reflete no desenvolvimento da perspectiva de atendimento geral e com isso podem-se ter um retorno positivo no que diz respeito a produção e recuperação do ambiente.

No Brasil alguns debates relacionados ao meio ambiente ganharam destaque a partir da Agenda 21 que indicou a evolutiva substituição dos modelos agropecuários e florestais que foram historicamente baseados em monoculturas para sistemas diversificados, com práticas de conservação e preservação ambiental.

O sistema de agricultura convencional é o que mais aparece em brejos de altitude e está diretamente ligado a economia da região na mesma proporção da degradação que provocou ao longo dos anos. Diante disso, pensar crescimento econômico e as relações de preservação e conservação ambiental em brejos de altitude requer o esforço de reorganizar a produção agropecuária no seio de seus sistemas produtivos, a fim de avançar no processo de recuperação de áreas degradas, redefinir uso e ocupação do solo, estimular 
práticas de convivência com a estiagem e criar formas de preservação da biodiversidade, sabendo entretanto, que esta é uma demanda do país como um todo e principalmente do semiárido .Este debate deve respeitar, contudo, a antropização existente e a demanda de recursos naturais associadas ao avanço do uso das diferentes tecnologias ambientais. Deve-se construir sistemas sustentáveis de produção adequados as condições edafoclimáticas da região.

Segundo Souza (2004) tais questões agropecuárias dependem da parceria do governo e da sociedade - sobretudo das populações e dos poderes existentes em cada uma das localidades - para que sejam reduzidos os monocultivos e as práticas de degradação. Estes, pela sua própria extensão, desvinculada das questões ambientais, têm simplificado perigosamente a paisagem e reduzido grande parte da vegetação nativa à condição de ilhas ou fragmentos florestais.

O cenário da situação ambiental atual desta região de brejo de altitude oriundo principalmente dos sistemas produtivos de modo geral exige um novo modelo produtivo que garanta sustentabilidade e ao mesmo tempo promova uma recuperação gradativa da área já degradada. Sistemas de atividades integradas tendem a ganhar espaço diante desse cenário. Isso se dá por que além dos ganhos técnicos, as propriedades com atividades integradas contribuem para a sustentabilidade de produção e para o bem-estar social no meio agrícola, uma vez que há proteção a recursos do meio ambiente, como a água, a microbiota edáfica benéfica, insetos, outros organismos que atuam como inimigos naturais, dentre outros. Adicionalmente, as atividades possibilitam a otimização na utilização dos recursos da propriedade, principalmente a mão-deobra o que promove estímulo à agricultura familiar a geração de empregos locais melhorando a economia da região.

Sabe-se, porém, que inúmeros desafios estão postos na atualidade. Dentre eles, cabe ressaltar que as mudanças perpassam pelo surgimento de novas tecnologias ambientais, a capacitação profissional em práticas conservacionistas, um novo modelo de organização social de produtores, organização do mercado em cadeias produtivas, uma reforma agrária popular e o avanço das pesquisas voltadas ao desenvolvimento rural sustentável. Vale ressaltar ainda que, segundo Guimarães (2019), para haver a otimização na produção é necessário realizar um planejamento agrícola, sendo importante o levantamento das características e propriedades dos recursos solo, água e vegetação, bem como sua espacialização na paisagem geral

A questão de qual modelo implantar em regiões de brejos de altitude requer uma análise holística da realidade que passa por uma série de indicadores de sustentabilidades existentes ou a serem criados e que requer incentivos técnicos, financeiros e políticos de todos os atores. Vale destacar que nenhum modelo fechado é suficiente para todas as regiões. Cada local e sua especificidade deve ser respeitada como princípio de um desenvolvimento rural sustentável eficaz e eficiente.

\section{CONCLUSÕES}

As culturas tradicionais estão passando por um processo de perda de produção vinculados a fatores ambientais e climáticos; A redução de áreas de florestas naturais está ligada ao processo de produção agropecuária; A introdução de novas culturas é um fator limitante no processo de redução na produção das 
atividades tradicionais; Culturas voltadas ao confinamento e produção com rentabilidade rápida estão sendo um meio de troca em relação as culturas tradicionais.

\section{REFERÊNCIAS}

ALBUQUERQUE, U. P.; ANDRADE, L. H. C.. Uso de recursos vegetais da caatinga: o caso do agreste do estado de Pernambuco (Nordeste do Brasil). Interciencia, v.27, n.7, p.336-346, 2002.

ARAÚJO, S. M. S.. Tempo, espaço e biogeografia. In: RODRIGUES, A. F.; SILVA, E.; AGUIAR, J. O.. Natureza e cultura nos domínios de clio: história, meio ambiente e questões étnicas. EDUFCG, 2012. p.155-176.

BARBOSA, M. R. V.; AGRA, M. F. E.; SAMPAIO, V. S. B.; CUNHA, J. P.; ANDRADE, L. A.. Diversidade florística na Mata do Pau-Ferro, Areia, Paraíba. Brejos de Altitude em Pernambuco e Paraíba: história natural, ecologia e conservação. Brasília: Ministério do Meio Ambiente, 2004.

BARROS JÚNIOR, A. P.; SOUZA, W. M.; ARAÚJO, M. S. B.. Produção de farinha da mandioca no agreste pernambucano. Revista Equador, v.5, n.5, p.216-238, 2016.

BOTELHO, I. G. S. O.. Crescimento e produtividade de variedades de cana-de-açúcar em brejo de altitude no estado da Paraíba. Monografia (Bacharelado) - Universidade Federal da Paraíba, João Pessoa, 2019.

CARDOSO, J. C.. Cultivo e produção de mandioca (Manihot esculenta Crantz). São Carlos: EDUFSCAR, 2012.

DANTAS, J. L. L.; SHEPHERD, K.; SILVA, S. D. O.; SOARES FILHO, W. D. S.. Classificação botânica, origem, evolução e distribuição geográfica. In: A Cultura da Banana: aspectos técnicos, socioeconômicos e agroindustriais. 1997. p.27-34.

FAGERIA, N. K.; STONE, L. F.. Produtividade de feijão no sistema plantio direto com aplicação de calcário e zinco. Pesquisa Agropecuária Brasileira, v.39, n.1, p.73-78, 2004.

FERREIRA, J. D. C. Condições de preservação dos recursos hídricos em microbacias em brejos de altitude no semiárido pernambucano. Dissertação (Mestrado) - Universidade Federal de Pernambuco, Recife, 2018.

FRANÇA, L. R.; SOUZA, J. G.; MORAES, V. M. B.. Comparação de dois modelos de produção de frangos de corte. Archivos de Zootecnia, v.56, n.215, p.359-362, 2007.

FREITAS, M. A.; ABEGG, A. D.; ARAÚJO, D. S.; COELHO, H. E. A.; AZEVEDO, W. S.; CHAVES, M. F.; MOURA, G. J. B.. Herpetofauna of five" Brejos de Altitude" of the interior of the state of Pernambuco, Northeastern Brazil. Herpetology Notes, v.12, p.591-602, 2019.

GIL, A. C.. Métodos e técnicas de pesquisa social. 6 ed. Atlas SA, 2008.

GUIMARÃES, H. S.. Estimativa do balanço hídrico como ferramenta para planejamento agrícola no brejo paraibano. Monografia (Bacharelado) - Universidade Federal da Paraíba, João Pessoa, 2019.
HAGUETTE, A.; HAGUETTE, T. M. F.. Metodologias qualitativas na Sociologia. Revista Brasileira de Estudos Pedagógicos, v.75, n.179, p.80-81, 2007.

LAURENTINO, M. L. S.; SILVA, H. A.; SILVA, J. C. B.; SANTANA, S. H. C.; MORAIS, Y. C. B.; GALVÍNCIO, J. D.. Aplicação dos índices de NDVI e EVI como análise da variação fisionômica da vegetação no Brejo de Altitude de Serra NegraBezerros/PE-Brasil. In: SIMPÓSIO BRASILEIRO DE SENSORIAMENTO REMOTO, 15. Anais. 2011. p.3182-3189.

LIMA, D. A.. Estudos fitogeográficos de Pernambuco. Recife: Instituto de Pesquisa Agronômica de Pernambuco, 1960.

LIMA, D. A.. Present-day forest refuges in northeastern Brazil. Biological Diversification in the Tropics, v.245, p.251 1982.

LINS, R. C.. Áreas de exceção do Agreste de

Pernambuco. Recife: Sudene, 1989.

LORENZI, J. O.. Aspectos fitotécnicos da mandioca em Mato Grosso do Sul. Aspectos do Cultivo da Mandioca em Mato Grosso do Sul. Dourados: Embrapa Agropecuária Oeste, 2002.

MARCONI, M. A.; LAKATOS, E. M.. Metodologia científica. 5 ed. São Paulo: Atlas, 2007.

MARENGO, J. A.; CUNHA, A. P.; ALVES, L. M.. A seca de 201215 no semiárido do Nordeste do Brasil no contexto histórico. Revista Climanálise, v.3, p.49-54, 2016.

MARQUES, A. L.; SILVA, J. B.; SILVA, D. G.. Refúgios úmidos do semiárido: um estudo sobre o Brejo de Altitude de Areia/PB. Revista Geotemas, v.4, n.2, p.17-31, 2014.

MARTINS, E. S. P. R.; MAGALHÃES, A. R.. A seca de 2012 2015 no Nordeste e seus impactos. Parcerias Estratégicas, 2015.

MATSUURA, F. C. A. U.; COSTA, J. I. P.; FOLEGATTI, M. I. S.. Marketing de banana: preferências do consumidor quanto aos atributos de qualidade dos frutos. Embrapa Mandioca e Fruticultura, 2004.

MEDEIROS, J. F.. Da análise sistêmica à Serra de Martins: contribuição teórico-metodológica aos brejos de altitude. 2016.

MEDEIROS, J. F.; CESTARO, L. A.. Os Brejos de Altitude no contexto das Áreas de Exceção do Nordeste brasileiro. Revista de Geociências do Nordeste, v.4, p.126146, 2018.

MEDEIROS, R. L. S.; SOUZA, V. C.; ARBOSA NETO, M. A.; ARAÚJO, L.. Estrutura da regeneração natural de Anadenanthera colubrina em fragmento de brejo de altitude 
em Bananeiras, PB. Pesquisa Florestal Brasileira, v.36, n.86, p.95-101, 2016.

MEDEIROS, R. L. S.; SOUZA, V. C.; SANTOS, J. N. B.; AZEREDO, G. A.; ANJOS, F.. Ecofisiologia de sementes em brejo de altitude na Paraíba visando à conservação da biodiversidade autóctone. Ciência Florestal, v.27, n.2, p.697-705, 2017.

NASCIMENTO, E. L. L.. Relações filogenéticas de líquens da Amazônia, Mata Atlântica e Caatinga. 2017.

PEREIRA, G. A.; DANTAS, S. D. M.; SILVEIRA, L. F.; RODA, S. A.; ALBANO, C.; SONNTAG, F. A.; LEES, A. C.. Status of the globally threatened forest birds of northeast Brazil. Papéis Avulsos de Zoologia, v.54, n.14, p.177-194, 2014.

PINO, F. A. S.; FRANCISCO, V. L. F.; PEREZ, L. H.; AMARO, A. A.. A cultura da banana no Estado de São Paulo. Informações Econômicas-Governo do Estado de São Paulo Instituto De Economia Agrícola, v.30, n.6, p.45-75, 2000.

PONZONI, F. J.; SHIMABUKURO, Y. E.; KUPLICH, T. $M$.. Sensoriamento remoto da vegetação. Oficina de Textos, 2015.

RIBEIRO, J. K. N.; VITORIANO, U. S.; SILVA, E. B.. Solos, manejo e processos erosivos em brejos de altitude. Conidis, 2016.

ROUSE, J. W.; HAAS, R. H.; SCHELL, J. A.; DEERING, D. W. Monitoring vegetation systems in the great plains with ERTS. In: EARTH RESOURCES TECHNOLOGY SATELLITE-1 SYMPOSIUM, 3. Anais. Washington, 1973. p.309-317.

SANTOS, B. A.; PERES, C. A.; OLIVEIRA, M. A.; GRILLO, A.; COSTA, C. P. A.; TABARELLI, M.. Drastic erosion in functional attributes of tree assemblages in Atlantic forest fragments of northeastern Brazil. Biological Conservation, v.141, n.1, p.249-260, 2008.

SANTOS, J. P. A.; SILVA, C. V.; SILVA, R. S.; LIMA, F. J.. Análise geoambiental do brejo de altitude de água branca: um estudo de caso no povoado papa terra, alagoas. Revista da Casa da Geografia de Sobral, v.21, n.2, p.637-645, 2019. DOI: https://doi.org/10.35701/rcgs.v21n2.604

SANTOS, L. S.. Estudo das alterações na cobertura vegetal ao longo de perfil topográfico, com ênfase em enclave de cerrado no agreste meridional de Pernambuco, Brasil. Dissertação (Mestrado) - Universidade Federal de Pernambuco, Recife, 2014.
SILVA, I. S.; VASCONCELLOS, A.; MOURA, F. M. S.. Termite assemblages (Blattaria, Isoptera) in two montane forest (Brejo de Altitude) areas in northeastern Brazil. Biota Neotropica, v.19, n.1, 2019.

SILVA, M. C.; SILVINO, G. S.; SILVA, M. C.. Da abundancia hídrica a escassez de água residencial: as particularidades hidroterritoriais no. Revista Desenvolvimento Social, v.19, n.3, p.21-36, 2019

SILVEIRA, L. F.; OLMOS, F.; LONG, A. J.. Birds in Atlantic Forest fragments in north-east Brazil. News \& Reviews Features, p.1832, 2003

SOUZA, M. N.. Degradação e recuperação ambiental e desenvolvimento sustentável. Viçosa: UFV, 2004.

TABARELLI, M.; SANTOS, A. M. M.. Uma breve descrição sobre a história natural dos brejos nordestinos. Brejos de Altitude em Pernambuco e Paraíba, História Natural, Ecologia e Conservação, v.9, p.17-24, 2004.

TAVARES, M. C. G.; RODAL, M. J. N.; MELO, A. L.; ARAÚJO, M. F.. Fitossociologia do componente arbóreo de um trecho de floresta ombrófila montana do Parque Ecológico João Vasconcelos Sobrinho, Caruaru, Pernambuco. Naturalia, v.25, n.1, p.243-265, 2000.

VASCONCELOS SOBRINHO, J.. As regiões naturais do Nordeste, o meio e a civilização. Recife: Conselho de Desenvolvimento de Pernambuco, 1971

VIANA, V. M.. Dynamics and restoration of forest fragments in the Brazilian Atlantic moist forest. Tropical forest remnants: ecology, management, and conservation of fragmented communities. 1997.

VIGANÓ, H. A.; BORGES, E. F.; ROCHA, W. J. S. F. Análise do desempenho dos Índices de Vegetação NDVI e SAVI a partir de imagem Aster. In: SIMPÓSIO BRASILEIRO DE SENSORIAMENTO REMOTO, 15. Anais. Curitiba: INPE, 2011.

VON LÜTZOW, M.; KNABNER, I. K.. Temperature sensitivity of soil organic matter decomposition-what do we know?. Biology and Fertility of Soils, v.46, n.1, p.1-15, 2009.

ZENS, S. D.; BARIONI, L. G.; BONATO, D. B. B.; ALMEIDA, M. H. S. P.; RITTI, T. F.. Pecuária de corte brasileira: impactos ambientais e emissões de gases efeito estufa (GEE). Piracicaba: Cepea, 2008.

A CBPC - Companhia Brasileira de Produção Científica (CNPJ: 11.221.422/0001-03) detém os direitos materiais desta publicação. Os direitos referem-se à publicação do trabalho em qualquer parte do mundo incluindo os direitos às renovações, expansões e disseminacões da contribuicão, bem como outros direitos subsidiários. Todos os trabalhos publicados eletronicamente poderão posteriormente ser publicados em coletâneas impressas sob coordenação da Sustenere Publishing, da Companhia Brasileira de Produção Científica e seus parceiros autorizados. Os (as) autores (as) preservam os direitos autorais, mas não têm permissão para a publicação da contribuição em outro meio, impresso ou digital, em português ou em tradução. 